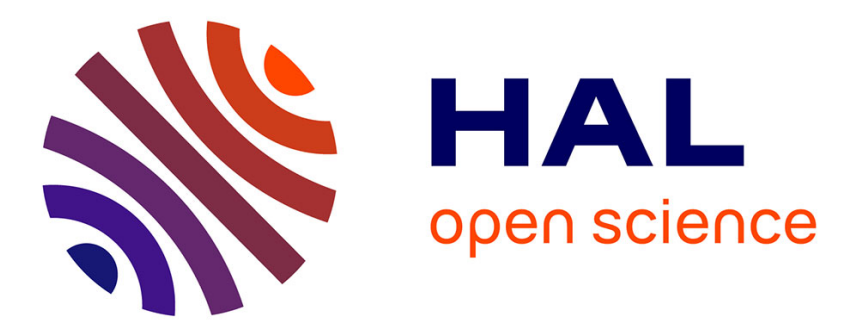

\title{
From archaeological sites to nanoscale: the quest of tailored analytical strategy and modelling
}

\author{
Ludovic Bellot-Gurlet, Philippe Dillmann, Delphine D. Neff
}

\section{To cite this version:}

Ludovic Bellot-Gurlet, Philippe Dillmann, Delphine D. Neff. From archaeological sites to nanoscale: the quest of tailored analytical strategy and modelling. Dillmann, Philippe; Bellot-Gurlet, Ludovic; Nenner, Irène. Nanoscience and Cultural Heritage, Atlantis Press, pp.205-230, 2016, 978-94-6239-1970. 10.2991/978-94-6239-198-7_7. cea-01634384

\section{HAL Id: cea-01634384 https://hal-cea.archives-ouvertes.fr/cea-01634384}

Submitted on 18 Oct 2020

HAL is a multi-disciplinary open access archive for the deposit and dissemination of scientific research documents, whether they are published or not. The documents may come from teaching and research institutions in France or abroad, or from public or private research centers.
L'archive ouverte pluridisciplinaire HAL, est destinée au dépôt et à la diffusion de documents scientifiques de niveau recherche, publiés ou non, émanant des établissements d'enseignement et de recherche français ou étrangers, des laboratoires publics ou privés. 


\title{
From archaeological sites to nanoscale: the quest of tailored analytical strategy and modelling
}

\author{
Ludovic Bellot-Gurlet ${ }^{1}$, Philippe Dillmann ${ }^{2}$, Delphine Neff ${ }^{2}$
}

1 Sorbonne Universités, UPMC Université Paris 6, MONARIS “de la Molécule aux Nanoobjets : Réactivité, Interactions et Spectroscopies”, UMR 8233, UPMC-CNRS, 75252 Paris Cedex 05, France

2 LAPA-IRAMAT, NIMBE, CEA, CNRS, Université Paris-Saclay, CEA Saclay 91191 Gifsur-Yvette, France

\begin{abstract}
Last developments of nano probes allows scientists of Cultural Heritage to assess a new kind of information that is crucial in the different topics concerned by the field: determining ancient manufacturing processes, studying use and provenance of ancient artefacts, revealing the degradation processes and developing adapted cleaning and conservation treatments. Nevertheless to be useful, these nanoscale approaches must be integrated in a tailored multi-step analysis. The final aim of these approaches will be to reach understanding and/or reliable modelling of the behaviours of the ancient systems. A first part of this chapter will review the issues in Cultural Heritage and the nature of the physico-chemical data that can be collected on the systems. In a second part, a selection of examples dealing with nano characterisation in Cultural Heritage will allow us to present several up to date techniques and methodologies employed in Cultural Heritage science. Then, the third part of the chapter will review some of the different modelling attempts that where already made in the domain of Cultural Heritage, and that were based on the use of physico-chemical descriptions at different scales. The challenge for the next future will be, for different kind of materials and environments, to propose multiscale models from nano to functional scale. Some key steps to face these challenges bridging the gap between multiscale descriptive characterisation and numerical modelling are reviewed here.
\end{abstract}

\section{Introduction}

The different chapters of this book demonstrated on the one hand the pertinence of looking at physico-chemical systems of Cultural Heritage at the nanometre scale, on the other hand the fact that, despite the absence of measurement tools to observe them at nanometre scale, ancient craftsmen's mastered the control of nanoparticules and nano-structuration for some marvel of ancient technical realisation 
(metallic lustres, ceramics, etc). For studying such nano-structures or understanding the properties originating from the nano-scale, the development of nanoprobes or nano-investigation techniques is called to increase in heritage studies. Nevertheless, an investigation at the nano-scale alone does not allow an expert of heritage science to understand the system under investigation and to answer to the scientific question asked. Therefore this is only by integrating this nanometer scale approach in a tailored multi-step and multi-scale scientific and analytical methodology that the "nanometer scale will make sense".

Thus, today challenges and breakthrough are double:

- to develop the use of accurate and efficient nanoprobes or nanometre scale investigation techniques in multistep methodologies,

- to bridge the gap between the different scales, concerning the understanding of Cultural Heritage systems and/or the modelling of their behaviour.

The first aspect is, still today, linked by a limited access to the nanometre scale investigation methods. This is chiefly due to financial reasons limiting the widespread of devices and associated analytical know-how. Moreover most of the time experiments at nanoscale are costly and time consuming. This is an additional reason to integrate them in a step to step analytical strategy, beginning with reliable macroscopic investigation methods and a careful selection of the representative sample at a given scale. Then, at the end of the process, only the most representative sample should be submitted to nanometre observation, avoiding waste of time and means. To that purpose, and to help scientist of Cultural Heritage to develop right analytical strategies, the first part of this chapter will present a brief review of the various aspects of physico-chemical issues, at different scales of investigation, linked to the systems of Cultural Heritage.

To select the most adapted nanoscale investigation method it is necessary, for the conservation scientist or the scientist practicing archaeometry who will implement it in close collaboration with the specialist of the method, to have in mind the potentiality of the different available methods and the nature of the information they can deliver. This is the aim of the second part of this chapter that will give a tentative overview, through selected and concrete examples, of the cutting edge techniques used in the field of heritage but also in some related domains of research that have comparable scientific and analytical concerns.

The second aspect, aiming to bridge the gap between the different scales, may seem to be trivial but is not. This issue is not restricted to Cultural Heritage materials, but it is a crucial issue in other domains of science dealing also with heterogeneous materials in which a nanometre scale process can be (or not) at the origin of a macroscopic behaviour at the functional scale (environmental science, material science, etc.). The synergy of different potential mechanisms and processes happening at different scales renders the interpretation and the evaluation of the dominant parameter or mechanism (if there is one) very difficult. To reach that goal, we believe that a very important, challenging and promising research direction is linked to the multiscale modelling of such systems. This modelling, even by being only descriptive (and not predictive) will allow one to better understand 
the role of the different parameters and their respective influence on the macroscopic behaviour. In the most favourable case they could be able to predict the future of Cultural Heritage systems, being a wonderful tool for our societies that have the duty to transmit the Cultural Heritage and its knowledge to the next generations. These aspects will be detailed in the third and last part of the present chapter, reviewing the modelling attempts in the domain of Cultural Heritage research and pointing the challenges for the forthcoming researches that will try to develop multiscale models.

\section{Issues dealing with "Heritage systems"}

Listing or reviewing all the studies dealing with "material aspects" and Heritage is not straightforward. According to the review or book aim, author background or specialities, it will focus on, or highlight, various aspects of the numerous facets of heritage systems or studies (for examples: Pollard and Heron 2008; Colombini and Modugno 2009; Casadio and Van Duyne 2013; Physical techniques in the study of Art, Archaeology and Cultural Heritage 2006 ; Edwards and Vandenabeele 2012; Madariaga 2015; Dillmann and Bellot-Gurlet 2014).

For issues dealing with analytical studies, then focusing on objects or materials, one could try to depict the Heritage problematics through a simplified object life pathway (Fig. 24). All objects start from some raw material, which could be manufactured only by shaping, grinding (or any transformations without chemical changes), or through techniques/processes, which will transform the constituents to obtain some new materials. Societies and their knowledge could be studied through their ability of knowing their environment/resources, the ways for exploiting resources, the abilities for procurement and distribution of goods, and the techniques to manufacture objects or materials for specific uses or purposes, all these aspects describing a technical (and even sometimes technological) level and relations between societies and their natural environment. During history a wide dynamic exists, according to places, cultures, their interactions and evolutions. Many studies in the field of Cultural Heritage aim to reconstruct the history of some materials' use, some techniques or some technical gesture. This especially thanks to the information that analytical methods deliver to identify raw materials, their geographic origin or reveal ancient techniques. All these clues are linked to physico-chemical features of the constituent of the materials/artefacts.

After being manufactured objects were used, and according to some use wear or residues the human activities related to objects could be clarified (as stone tools (Astruc et al. 2011) or ceramics contents (Evershed 2008). An important aspect is also the recycling practices that can be investigated by analytical approaches. 


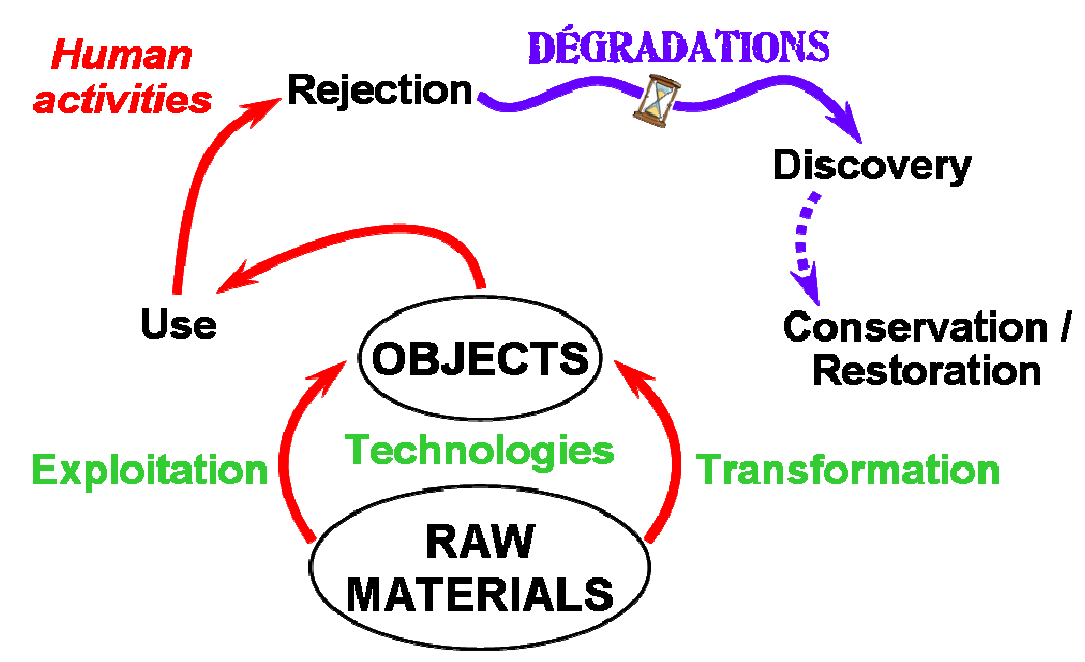

Fig. 24. Illustration of the life cycle of objects

Before being transmitted to the present, objects and masterpieces could remain "in use" (as buildings, mural or canvas paintings, etc.) or buried by constituting the archaeological sites. Along time, with multisecular duration, degradation mechanisms modified the objects leading sometimes to their complete change (according to their nature and their environment). For heritage studies, first the effects of these degradations need to be understood for being able to differentiate them from information related to previous object life. Second, if this testimony of past societies is decided to be conserved for future generations, one must understand the running degradation mechanisms in order to be able to diagnose the stability of the object and recommend some conservation policies, strategies or treatments. On the other hand, in order to be presented to a public, an object should be "easily" understood and thus some adapted restoration treatments need to be developed and undertaken in compliance with existing guidelines (as UNESCO, International Council of Museums-Committee for Conservation $(\text { ICOM-CC })^{6}$ and the International Centre for the Study of the Preservation and Restoration of Cultural Property ${ }^{7}$ ).

Dealing with "heritage systems", requires to apprehend all the scales/systems that constitute it: from a small artefact/object, to a building and a whole site and its environment. Just taking into account the system studied, problems are multiscaled, with interactions between the scales or parts of objects/systems. Addressing these challenges requires the development of adapted analytical strategies and concepts to make the links between on one hand, measures and scales, and on the other hand, studied systems and problematics. Such challenges are the daily work of scientists and Cultural Heritage experts.

\footnotetext{
${ }^{6}$ http://www.icom-cc.org/

${ }^{7}$ http://www.iccrom.org/
} 
Thus, for each of these stages of the life (and vanishing) of heritage systems, and for their protection and conservation, different issues arise, linked to historical, cultural or conservation purposes. These issues can be expressed in terms of scientific concepts or questions. Then, to answer these questions, specific physicochemical parameters must be measured on the systems. These measurements must be made at different scales, from the nanometre to the functional scale, in order to determine the synergies between these scales and pertinent (dominant) processes. These scientific questions and parameters are summed up in Table 1.

Concerning the manufacturing processes (from transformation of raw materials to secondary and final elaboration of artefacts), the key issues are linked to the determining of the raw materials (nature and origin) and the nature (temperature, chemical conditions, duration, efficiency, etc.) of the processes.

The first issue linked to historical aspects is the determination of supply network of goods and raw materials in ancient societies. This is linked to the crucial question of provenance and circulation of materials and artefacts. Determining the chemical compositions of the trace elements (Leroy et al. 2012) and/or the isotopic composition (Brauns et al. 2013) can approach this. Because ancient systems and artefacts are per nature heterogeneous at different scales, and because these trace elements and isotopes are heterogeneously distributed in the material, investigation at different scales must here also be implemented.

The raw material selection is also involved in the manufacturing processes, as technologies are linked to the composition of the materials, but besides to the properties and reactivity of the constituents. This information can be reached by knowing the chemical composition (mainly of major or minor elements) but also and chiefly the nature of the phases in relation to their thermodynamic properties. The sizes of the different precipitates and aggregates in the systems are also crucial parameters to be determined. Lastly, linked to the duration and the efficiencies of the processes, transport phenomena, depending on temperatures, nature of media, phases and involved species are key parameters and can be understood. Transport mechanisms could be assessed by measuring the porosity of the system if they are porous (gaseous state transport), by the sizes of particles (implying active surfaces available) or by the nature of the phases in which solid state transport could happen (mostly at high temperatures).

If one considers now the use and the functions of the artefacts (tools, utensils, weapons, buildings, etc.) other questions must be considered. Beyond that shapes they are on the one hand linked to the aesthetical aspect of the materials (surface state, colour, ...), sometimes due to surface treatments, and on the other hand to the mechanical resistance and behaviour . To understand the first of these aspects, the nature (chemical and physical/optical) of the former surface layer (called limit of the initial surface by the conservation scientists (Bertholon 2001)) must be investigated. This implies to determine local composition and structural changes (including sizes of nanophases) at the location of the initial surface. The mechanical behaviour can be estimated with the nature of the material (composition) but also by its texture down to the micro and nano-structure (nature and organisation of phases and precipitates, linked to the move of dislocation for example). 


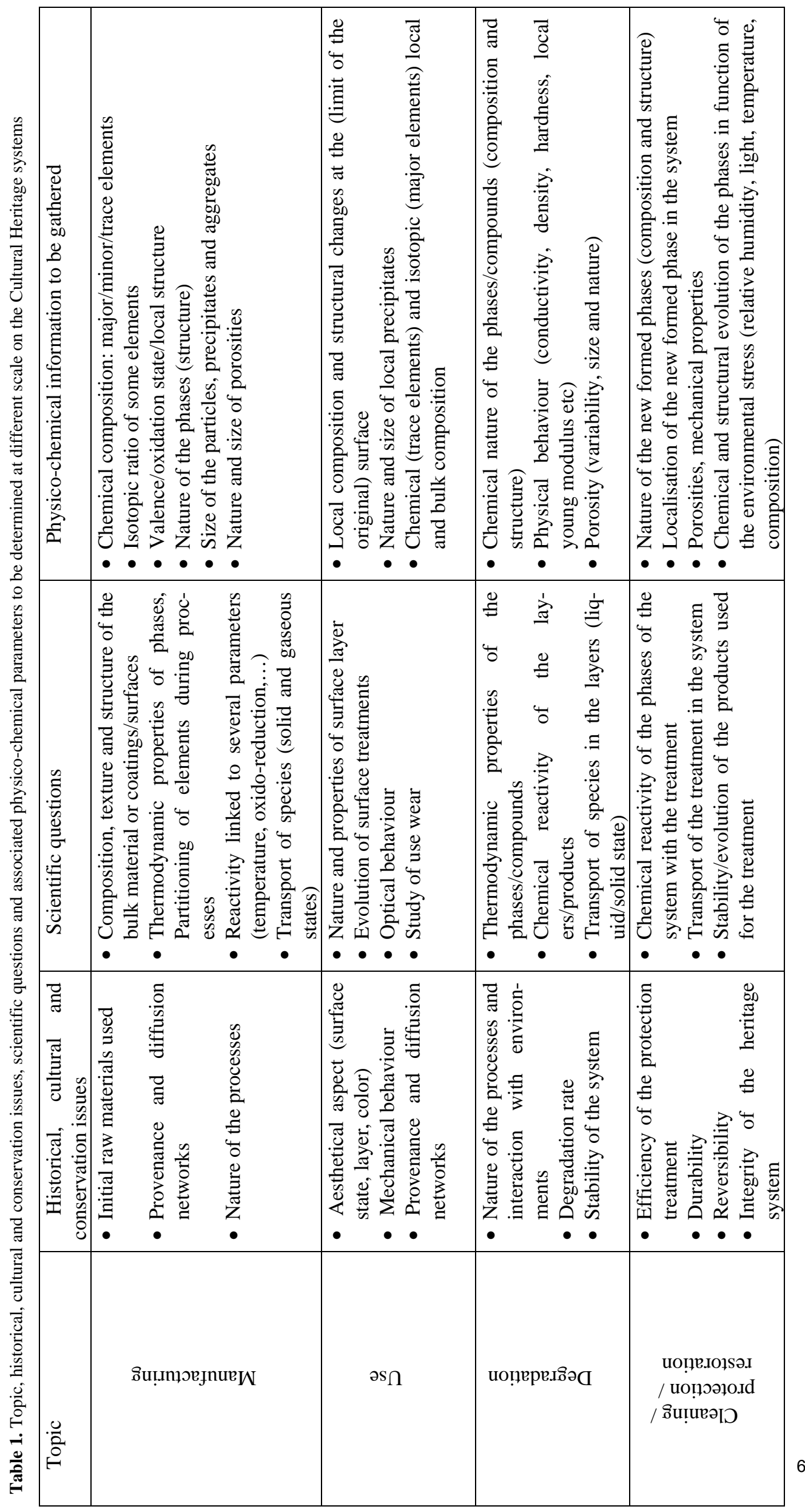


As far as degradation processes are involved, the challenges are here to determine the nature of the processes and the degradation rates linked to the stability of the systems in regards to their environments. This requires to assess to the thermodynamic properties of the phases but also their chemical and sometimes electrochemical reactivity and transport inside the alteration layers. These scientific questions need to determine here again the chemical and structural nature of the alteration layers at different scales, but also the chemical and physical properties (as reactivity, conductivity, hardness, density, etc.). Transport phenomena of species, the most of the time in porosities saturated in hydrous fluids and sometimes in solid state (vacancies, ions) in nanolayers, must also be considered.

Lastly, a crucial issue dealing with heritage is the setting up and the use of adapted cleaning, restoration and protection treatments. This topic needs to consider on the one hand the efficiency and durability of treatments but, also on the other hand the influence of this treatment on the integrity of the heritage system (modification of appearance, reversibility). This implies to characterise the nature (including chemical composition, structure and thermodynamic properties) of the new formed phases after interaction with the treatments, or the treatment product itself, but also to locate these compounds in the system and especially in the degradation system. Here again, in addition to the reactivity, the transport in the system (characterisation of porosities) is crucial. Lastly, the evolution under different environmental conditions of the new-formed phases (chemistry and structure) or the products used are key parameters to determine. Because the treated objects must be stable for the longest period, considering this behaviour requires a fine understanding of their durability properties over periods not mandatory for everyday life contexts.

\section{Analytical techniques}

\subsection{From macro to nano scales}

Analyses of Cultural Heritage materials and systems need specific protocols adapted to each context. The constraints on the sampling as well as the fragility of the artefacts can orientate the drawing of the analytical procedure. For that, the analytical set-up can be adapted to the potential various sample dimensions (from millimetre to decametre). As said before, characteristic of the samples are various and numerous and deals with the determination of their physical properties (among them: hardness, porosity, morphology of particles, conductivity), and their chemical properties mainly connected to their chemical composition and the nature and crystallinity of phases in presence. The choice of the most appropriate analytical technique to assess them is crucial to get the desired information. 
Most of the studies dealing with the nanoscale, namely the characteristics and properties of the material at the nanoscale, start with a multiscale analysis. Indeed, apart the difficulty to access to nanoprobe equipment (due to their high cost, then rare occurrence, especially in Cultural Heritage laboratories), answering scientific issues concerned by nanoscale properties often starts at first by surveys and studies at lower scales (i.e. macro and microscopic scales). This process needs a first analytical chain composed of classical devices and setups used in material sciences and described in details in previous publications (Edwards and Vandenabeele 2012). It is not in the scope of this chapter to describe it exhaustively. Yet it is important to insist on the fact that macro to microscale characterization prior to nanoscale analyses is unavoidable to ensure satisfying data acquisition and treatment. Actually the nanoscale analyses could be realized to the detriment of the representativeness regarding the totality and complexity of the studied artefacts. That is why the characterisation at the lower magnifications is required. First observations can be realized thanks to optical microscopy, especially when samples are prepared on sections which enlighten their heterogeneities. This provides information on the morphology and texture of the sample and allows one to locate the zones of interest for further analyses, by screening large surfaces and various samples. Additional observations can be obtained thanks to Scanning Electronic Microscopy (SEM). This analytical tool is the ultimate multiscale device thanks to its wide range of magnification. Particularly Field Emission Gun (FEG) SEM capable to work down to few nanometers resolution is a preferred technique to correlate information between micro and nanoscales.

In the following paragraph the different instruments working at the nanoscale are briefly presented, through selected examples. The aim is to illustrate the possibilities offered by these nanoscale techniques. Selected presented studies are mostly dealing with Cultural Heritage, and the authors hope that this overview will help new actors of the Cultural Heritage to enlarge the spectra of the techniques they can potentially use.

\subsection{Analyses at nanometer scale}

High Resolution X-ray Diffraction (HR-XRD) analyses can provide information on the sizes of nanocristallites present in the sampled materials, by using the Scherrer formula. For example Bayle (Bayle 2015) measured the crystallite sizes of akaganeite powders by XRD under synchrotron radiation to determine the effect of a dechlorination treatment on the progressive transformation of this chlorinated phase present in the corrosion layers of archaeological iron artefacts. Helary et al. (Hélary et al. 2003) measured the crystallite size of silver particles to understand the technology used in the medieval period for the production of metallic lustre ceramics. Another example, Ungár et al. (Ungár et al. 2002) studied by XRD under synchrotron radiation the crystallite size of black make-up of Ancient Egypt. Last a recent study used XRD under synchrotron to determine particle 
sizes on a range from the micrometric to the nanometric scale on various ancient materials like Roman terra sigillata, Neolithic flint (Fig. 2) or Roman iron nails (Dejoie et al. 2015). This was achieved thanks to a micrometric and monochromatic beam combined to the exploitation of Laue diffraction.

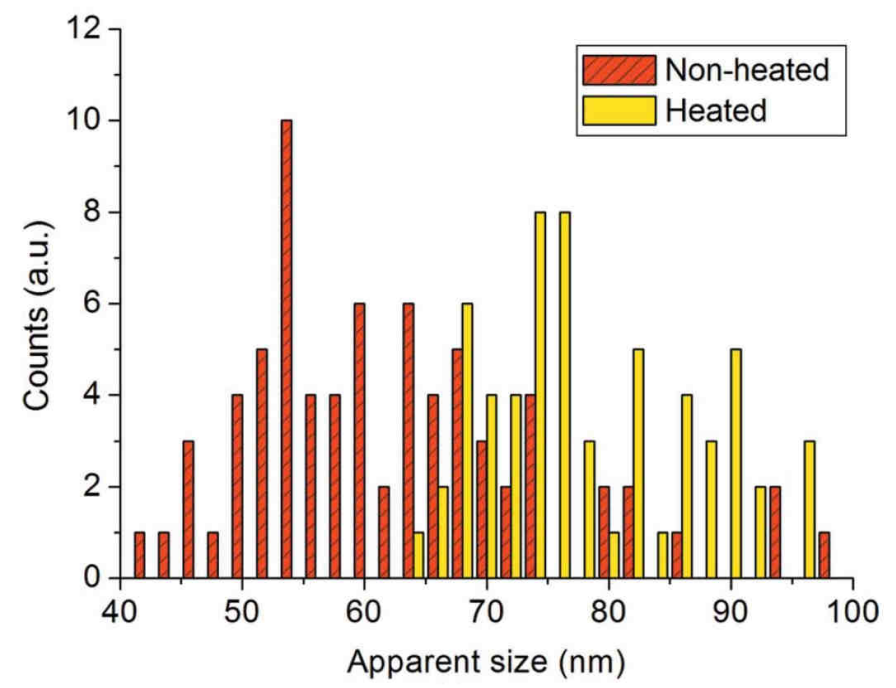

Fig. 25. Histogram of the apparent size of the coherently diffracting domains obtained after refinement of the powder data, showing a slight increase after the heating process of natural flints (Dejoie et al. 2015)

For surface analyses, Atomic Force Microscope (AFM) is one of the techniques used by few studies (Crina Anca Sandu et al. 2011), mainly dealing with the understanding of coatings like gilding or the assessment of protection properties for coatings protective treatments. This technique presents a lateral resolution, depending on the apex chosen for the surface probing, of about 10 nanometers. For example Ambrosi et al. (Ambrosi et al. 2001) studied the efficiency of the solvation of $\mathrm{Ca}(\mathrm{OH})_{2}$ in various organic solvent by AFM. The $\mathrm{Ca}(\mathrm{OH})_{2}$ is used to reinforce the wall paintings and the carbonic stones in the field of Cultural Heritage. The interest of AFM is to observe the dispersions of the nanoparticles in their solvents and to measure the sizes of the aggregates formed (Fig. 26).

Dal Bianco et al. (Dal Bianco and Bertoncello 2008) worked on mosaics recovered by a golden leaf. Initially the golden leaf was coated by a thin overlaying glass layer called cartellina but its weathering leave the golden leaf tessera unprotected. That is why they studied a protection treatment of this type of artefacts thanks to various sol-gel silica coatings. This latter was applied on model sample and the roughness of their surfaces was studied thanks to AFM. In the same way Manoudis et al. (Manoudis et al. 2009) studied the effect of siloxane based coatings on the enhancement of hydrophobic properties of stones. AFM was a complementary technique showing that the addition of $\mathrm{SiO}_{2}$ nanoparticles in the coat- 
ings conducts to the formation of nano-aggregates on the stone surface that impacts its colour. This consequence conducts the authors to recommend against adding nanoparticles in the coatings to respect the aesthetical aspect of the stone.

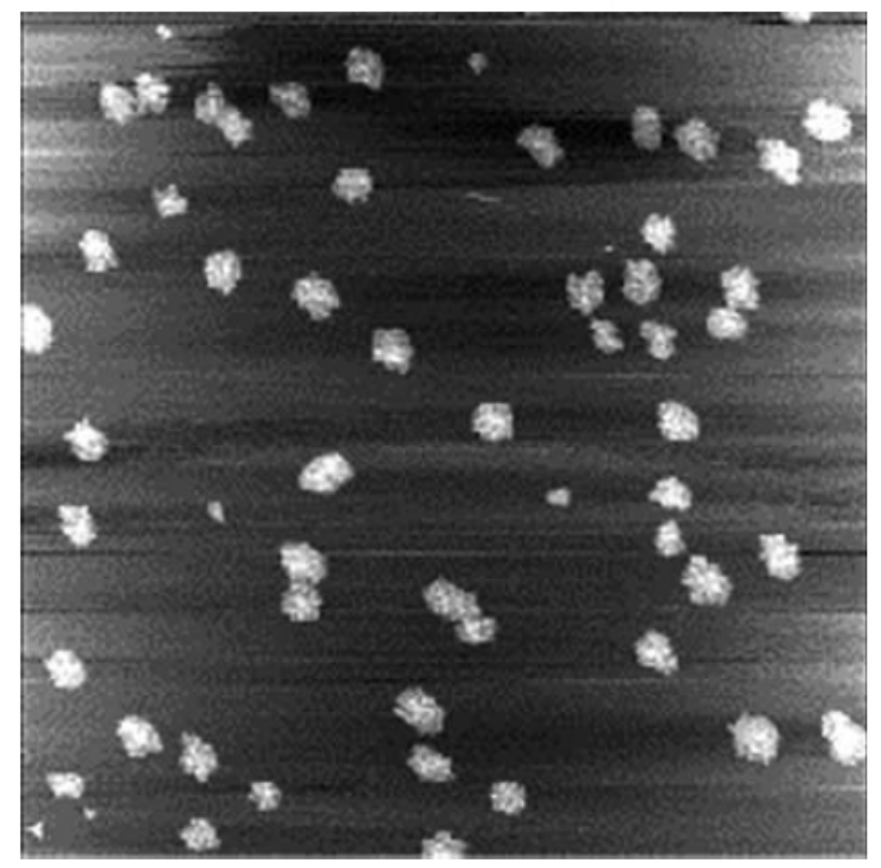

Fig. 26. Atomic Force image taken in a liquid phase (1 -propanol) of the $\mathrm{Ca}(\mathrm{OH}) 2$ nanoparticles obtained at $60^{\circ} \mathrm{C}$ : image dimensions $3.3 \mu \mathrm{m}$ x $3.3 \mu \mathrm{m}$, (Ambrosi et al. 2001)

Concerning the direct studies at the nanometric scale up to now the most used technique is the Transmission Electronic Microscope (TEM). This technique provides imaging with a resolution of less than 0.1 nanometer when a suitable preparation of the sample is realised. The electron beam is focused on the sample and images are recorded in transmission. In addition the electronic diffraction can provide structural analyses on the compounds observed. Moreover the interaction between the atoms of the sample and the electrons provokes the emission of X-rays providing qualitative and semi-quantitative information about the elementary composition of the samples thanks to the Energy Dispersive Spectroscopy (EDS). Last, the Electron Energy Loss Spectroscopy (EELS), although more delicate to interpret, can be used to provide information on the speciation of chemical elements present in the samples.

Complementary to AFM studies, the TEM imaging is used to determine the aggregates size used for the consolidation of stones (Baglioni et al. 2013). For example Chelazzi et al. (Chelazzi et al. 2013) and chapter 3.3 in this book, determined the aggregate size of $\mathrm{Ca}(\mathrm{OH})_{2}, \mathrm{Mg}(\mathrm{OH})_{2}$ or $\mathrm{Ba}(\mathrm{OH})_{2}$ dispersed in propanol. Yet, the control of the particle sizes and the polydispersity should be of the same 
range than the porosity of the treated surfaces. TEM is involved in this study to tailor these particles by varying the synthesis parameters. One other interesting example of TEM concerns the study of pigments sampled in ornamented prehistoric caves. In their studies Pomiès et al. and Chalmin et al. (Pomiès et al. 1998; Chalmin et al. 2004; Chalmin et al. 2006) have shown that many information can be obtained from a very low amount of pigments collected on the wall and deposited on a copper grid (Fig. 27).

Particularly in the case of the Lascaux cave different mineral phases have been identified depending on the colour: hematite $\left(\mathrm{Fe}_{2} \mathrm{O}_{3}\right)$ for the red, goethite $(\mathrm{FeOOH})$ for the yellow and mix of manganese oxides $\left(\mathrm{MnOOH}, \mathrm{MnO}_{2}, \mathrm{Mn}_{2} \mathrm{O}_{3}\right.$, $\mathrm{Mn}_{3} \mathrm{O}_{4}$ ) for the black pigments. Moreover the particle morphology indicates their crystallinity degree. Specifically for the hematite various class of low crystallinity or high crystallinity pigments have been established. Furthermore TEM imaging can document the pigment heating treatment as it revealed that the presence of porosity on hematite pigments is due to the deshydratation of a goethite $(\mathrm{FeOOH})$ when heated to obtain hematite (Pomiès et al. 1998). These nano-scale experiments provide indication of the mastering of heating treatment, highlighting the use of firing techniques for pigment preparation to produce red hematite from yellow goethite. Moreover TEM-EDS analyses indicate the presence of various minor elements that allows one to discriminate several pigments of the same mineral class, showing the possible correlation between different paintings panels and the paintings pots excavated in the cave. A last example of TEM is given by Leon $e t$ al. (Leon et al. 2015) with the observation of samples of terra sigillata, ceramics of the Roman period, which provides information about the technological transfer between Italy and Gaul. Indeed thanks to the complementarity with microXRD under synchrotron radiation, Raman spectroscopy, SEM and TEM, it has been evidenced that the technology of production has evolved between Italy where the production started and Gaul where this production was implemented. In this study TEM delivered information on the ceramic production process, particularly by showing the shape of the particles originated from the clay used for the production. In this case the shape and composition of particles were related to the firing temperature and the materials chosen to produce the terra sigillata.

Thanks to the development of synchrotron facilities, specific experiments are developed that allow one to obtain nanometer range beam (Sakdinawat and Attwood 2010). Among them another technique is getting involved in the characterisation of Cultural Heritage artefacts, the Scanning Transmission X-ray Microscopy (STXM). This microscopy is provided under synchrotron light source and consists in scanning a thin sample by a tuneable light to obtain a chemical image (or map). The energy chosen depends on the elemental composition of the sample. Through the scanning in energy around the absorption edge of an element $(\mathrm{K}, \mathrm{L}$ depending on the element), the XANES (X-ray Absorption Near Edge Structure) spectra can be reconstituted. The principal advantage of this technique is to deliver hyperspectral images that allow to preserve the information about the location on the samples of the extracted XANES spectra. 


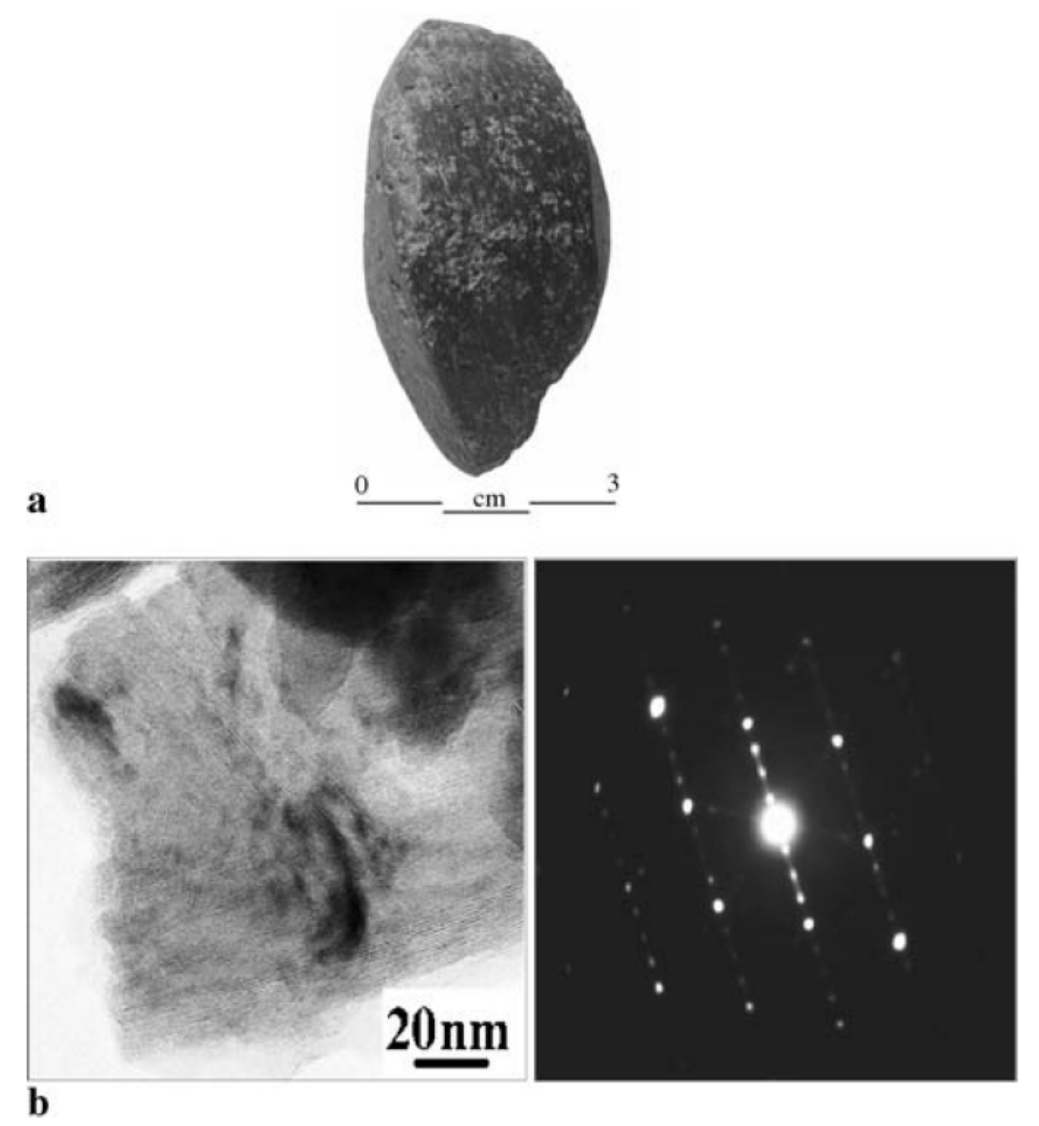

Fig. 27. (a) Black "crayon" of Combe Saunière, the only faceted block Marcillaud J.G. (b) G17C20 block of Combe Saunière: TEM micrograph of todorokite crystals identified by electron microdiffraction pattern ([001] zone axis single crystal), (Chalmin et al. 2006)

XANES provide structural data about the crystalline environment/speciation of a chemical element. Thus, it can help to determine the crystalline or amorphous nature of a phase as well as the oxidation degree of an element. STXM delivers a beam size of $25 \times 25 \mathrm{~nm}^{2}$ and is applied on thin samples of various thicknesses, depending on the composition of the sample and the chemical element that is studied. STXM is mostly used in material, geosciences or Natural Heritage as for example on fossils (Bernard et al. 2010; Galvez et al. 2009). One example of application on archaeological samples is given by Leon et al. (Leon et al. 2014). The aim of the study is to understand the corrosion mechanisms of ancient nails corroded in an anoxic soil. This study showed that an iron oxide layer of few hundred nanometers has precipitated at the interface with the metal. The sample of $100 \mathrm{~nm}$ thickness has been prepared by Focused Ion Beam (FIB-see below). As the whole corrosion layer of several hundred micrometer thickness is composed of an iron + II carbonate this interfacial oxide layer presents a mixed iron + II $/+$ III 
oxidation degree (Fig. 5). This specificity could confer to this thin layer specific conductive property that could play a major role in the control of the iron corrosion kinetics.

Synchrotron facilities also afford high resolution tomographic setups (Sakdinawat and Attwood 2010). For organic or light materials the spatial resolution of a voxel can reach $150 \mathrm{~nm}$. For example fossils of arthropods embryo dated from 520 million year old can now be studied in 3D, avoiding any invasive sampling. Their analyses reveal the presence of mouth, teeth and gut on a few hundred micrometer sample size. Some examples of X-ray fluorescence synchrotron nanotomography (SR-TOMO) are also provided by the planetary sciences that analysed stardust (Silversmit et al. 2009). This technique enables to analyse nondestructively the chemical composition of small samples.

(a)

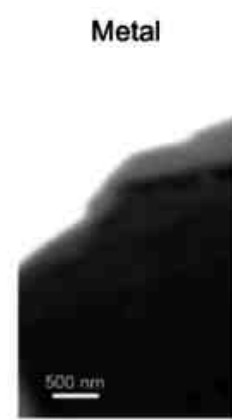

$0=100$

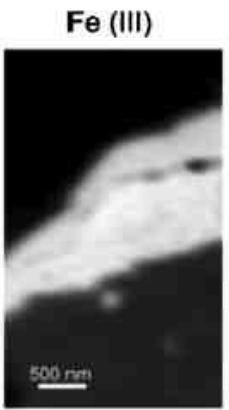

66

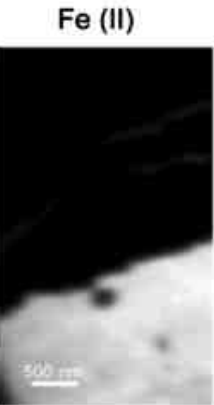

$0=69$

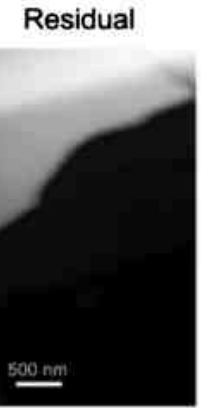

$0=1$ (b)

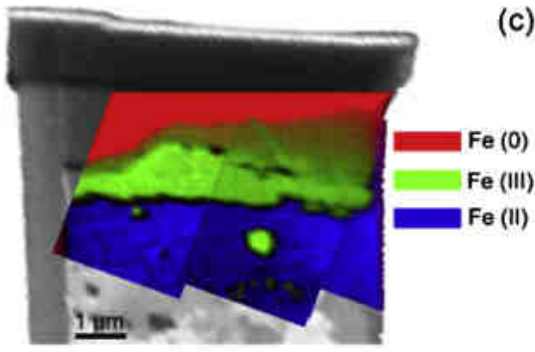

c)

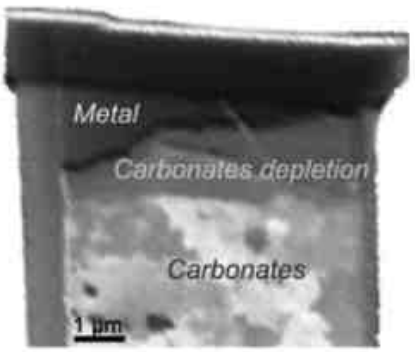

Fig. 28. STXM investigations of the sample thin film GL10-03: (a) SDV component maps of the $\mathrm{Fe}(\mathrm{III}), \mathrm{Fe}(\mathrm{II})$ and $\mathrm{Fe}(0)$ species obtained with the siderite, maghemite and metal reference spectra. Grey scales for $\mathrm{Fe}(\mathrm{II}), \mathrm{Fe}(\mathrm{III})$ and $\mathrm{Fe}(0)$ maps: equivalent thickness $(\mathrm{nm})$, for the residual map: optical density. (b) Overlay of the color-coded $\mathrm{Fe}(0), \mathrm{Fe}(\mathrm{II})$ and $\mathrm{Fe}(\mathrm{III})$ component maps (c) C K-edge difference map (290-280 eV) of the thin film. (Leon et al. 2014)

Back to laboratory, high spatial resolution facilities are nowadays developed. The Focussed Ion Beam (FIB) is one of them. This technique is based on the sample sputtering by a fine focused ion beam, generally gallium, allowing an efficient thin sample preparation for TEM or SEM. An additional interest is the coupling to a Scanning Electron Microscope (SEM). The specific interest of such dual-beam 
Focused Ion Beam Scanning Electron Microscopy (FIB-SEM) is to collect images during the milling, so that a volume of the sample can be 3D-imaged with a few tenth nanometers resolution. The first study in Cultural Heritage using the combination of FIB and SEM is illustrated by Giachi et al. (Giachi et al.). The authors observed archaeological waterlogged wood impregnated with colophony (Fig. 29). The milling of local surfaces allowed to observe with a high resolution the wood cell walls, showing that they were totally filled confirming the deposition of the colophony at least on the surface of the cells. A second example of preparation of sample thanks to FIB is given by Villanueva-Amadoz et al. (Villanueva-Amadoz et al. 2012). In their study these authors worked on the characterisation of palaeopalynological remains. Slice spores and pollen grains were sectioned by FIBSEM for reconstructing their ornamentation and wall-ultrastructure, providing information on their internal structure. King et al. (King et al. 2014) used 3D reconstruction by FIB-SEM to investigate the formation of cohesive calcium oxalate layers on marble surfaces for the conservation of stone. They used FIB-SEM complementary to SEM analyses to determine the 3D porosity network at a submicrometric scale showing that nanopores are partially connected inside a treated marble cube.

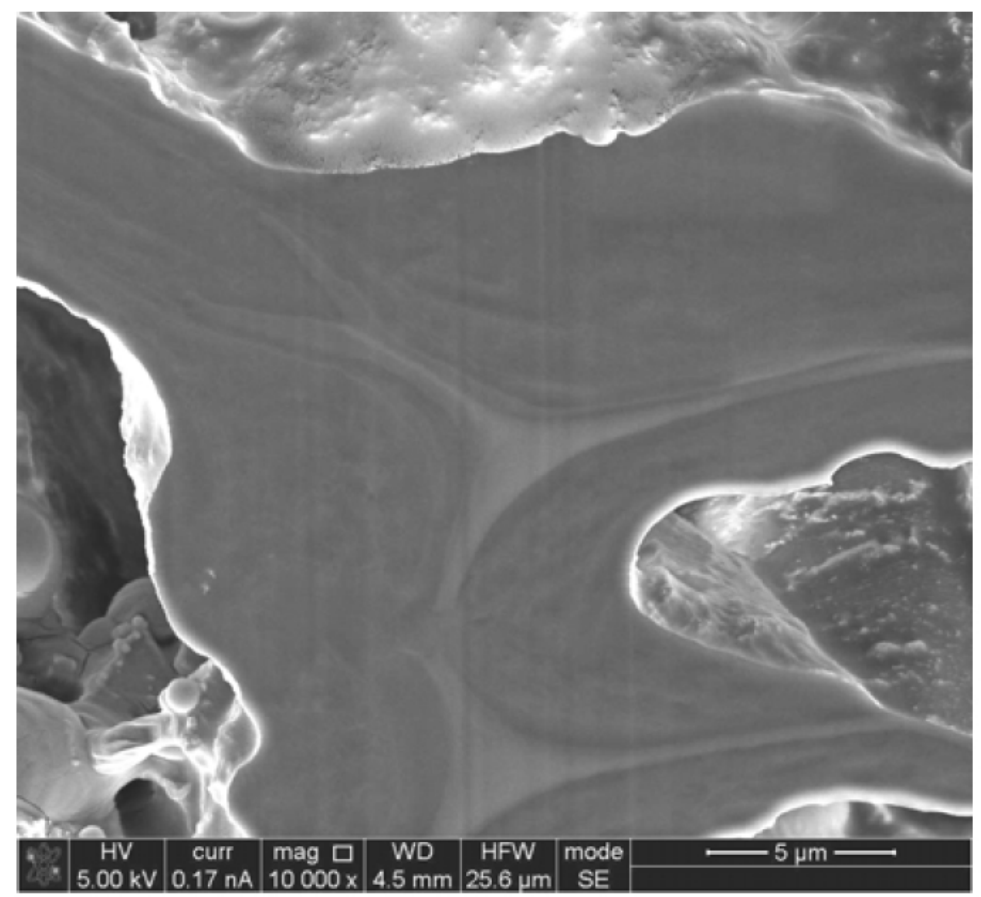

Fig. 29. FIB/SEM image of the cell wall of pine treated with colophony, Giachi et al. 
Various spectroscopies can now reach nanometric scales. In the UV-Visible spectroscopy with a synchrotron light source the analysed volume can be of a few hundred micrometers. Thoury et al. (Thoury et al. 2011) illustrated this technique on samples of ancient varnish of a musical instrument and on painting pigments containing $\mathrm{ZnO}$. The authors obtained mapping of the organic materials present in the varnish at the submicrometer scale. They also visualized the heterogeneities of the semiconductor pigment material. Tip Enhanced Raman Spectroscopy (TERS) thanks to the Near-field Scanning Optical Microscopy (NSOM) allows now the acquisition of Raman spectra with a nanometric resolution (Fleischer 2012). Few examples mostly related to the analyses of dyes are available in the literature. Kurouski et al. (Kurouski et al. 2014) analysed in situ indigo and iron gall ink on historical documents of the $19^{\text {th }}$ century. These techniques allowed the authors to identify pigments even at low concentration on the papers. Last, X-ray photoelectron spectroscopy (XPS) is a sensitive surface technique that provides chemical information on the few first hundred nanometers in the depth of materials but the lateral resolution is in the micrometric range. Nowadays, thanks to the coupling with synchrotron, X-ray photoelectron emission spectroscopy (XPEEM) can deliver lateral resolution of about $10 \mathrm{~nm}$. Among the few examples available in the Cultural Heritage field, De Stasio et al. (De Stasio et al. 2001) tested the surface of Roman silver coins. and conclude on the presence of fluorine that can avoid the tarnishing of the studied silver coins.

The principle of Secondary Ion Mass Spectrometry (SIMS) has been developed for various facilities that are able to deliver submicronic beams. Among them is the ToF-SIMS (Time of Flight SIMS) that can provide a $200 \mathrm{~nm}$ lateral resolution in specific acquisition modes. Complementary to this technique the nano-SIMS provides a beam of about $50 \mathrm{~nm}$ of lateral resolution. Both ToF and nano-SIMS allow one to analyse the chemical and isotopic composition of thin surface of the samples. They also work in mapping mode preserving the information on the location of the analyses. The principle of these techniques is to sputter ions on the sample surface, collect and analyse the masses of the ejected secondary ions. The mass/charge ratio is analysed thanks to a mass spectrometer that delivers the elemental and isotopic composition of the samples. ToF-SIMS (Fig. 30) has been used to analyse painting pigments (Richardin et al. 2011) or human skin remains (Cersoy et al. 2012). Concerning nano-SIMS, this technique is mostly used in the geoscience field (see for example (Hoppe et al. 2013)). One study dealing with the understanding of iron corrosion mechanisms focused on an archaeological nail of the $16^{\text {th }}$ century. In order to determine the transport properties inside the corrosion layer, it was immersed in deuterated water during 3 months (Leon et al. 2014). The nail was cut and prepared on transverse section. Thanks to the deuterium mapping at the interface with the metal, the authors showed that a micrometric interfacial layer was not porous, blocking the deuterated water penetration. 


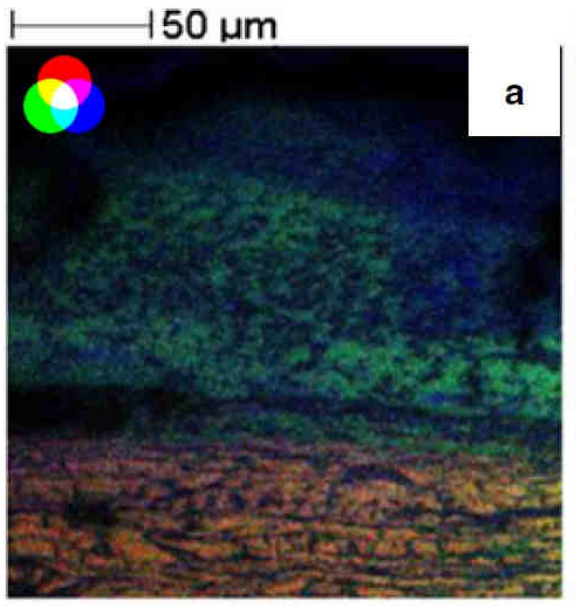

R: Hyp; G: Leu/lle; B: Ca

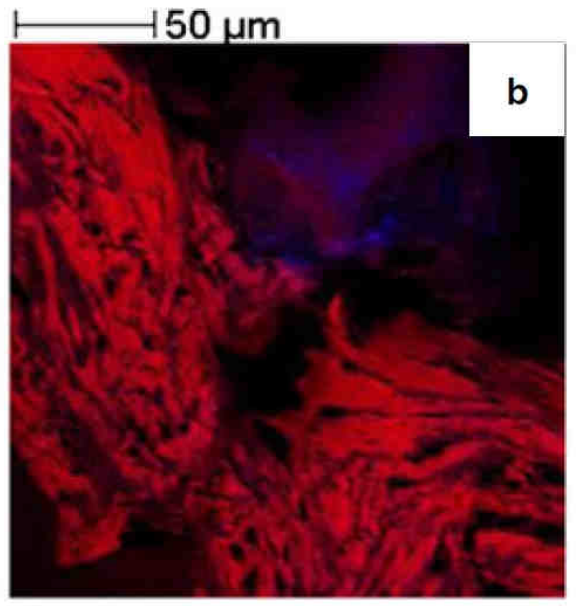

R: proteins; B: lipids

Fig. 30. High spatial resolution ion images of the skin cross section. (5a): Three color overlay between ion images (HYP: hydroxyproline fragment in red (R), leucine or isoleucine fragment in green $(\mathrm{G})$ and calcium ion in blue (B)). (5b): hypodermis area, two color overlay between ion images (protein backbone in red (R) and fatty acids in blue (B)). Field of view 200x200 mm2; 512x512 pixels, pixel size $390 \mathrm{~nm}$.(Cersoy et al. 2012)

Fig. 31 sums up in a simplified way the scales reached by the quoted nanotechniques and the nature of information they bring. It has to be stressed that, in this simplified view, the techniques at the micrometer are not taken into account, nor the possible requested sample preparation treatment (thin film, etc.) that can render the use of a given technique very tricky. Nevertheless, this short review demonstrates clearly that nanoscale techniques can provide unique information about the chemical composition and structure of ancient materials. Unfortunately, almost all of these techniques imply the sampling of heritage artefacts, not always allowed regarding conservation policies. Nevertheless, the constant improvement and development of new probes and micro-sampling solutions will facilitate their use on fragile or rare materials and thus improve their access for Heritage Science samples. 


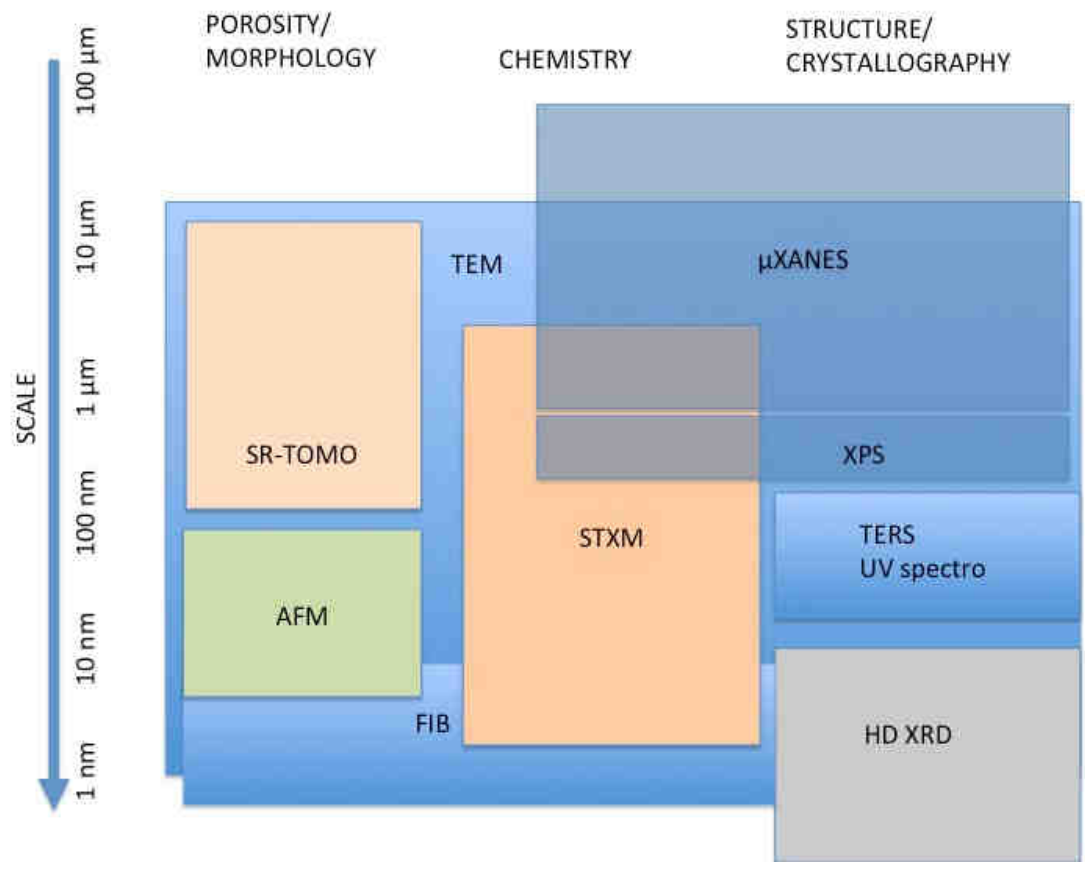

Fig. 31. Summary of the nanoscale techniques used in Cultural Heritage (SR-TOMO : X-ray tomography under synchrotron radiation, AFM : Atomic Force Microscopy, FIB-SEM: Focused Ion Beam Scanning Electron Microscopy, HR XRD: High Resolution X-ray Diffraction, STXM: Scanning Transmission X-ray Microscopy, TEM: Transmission Electron Microscopy, TERS: Tip Enhanced Raman Spectroscopy, ToF-SIMS: Time of Flight Secondary Ion Mass Spectrometry, XAS: X-ray Absorption Spectroscopy, XPS: X-ray Photoelectron Spectroscopy.

\section{From description at nanoscale to multiscale modelling: a new challenge for Cultural Heritage}

The first parts of the present chapter and the other chapters of this book (réf), show important examples of nano and, more generally, multiscale descriptions and analytical methods of systems linked to Cultural Heritage and ancient materials. These studies are more and more developed and tailored to assess crucial information on dimensioning parameters and to propose pertinent chemical mechanisms or processes. At the contrary very few attempts have been made, using these parameters, to model the behaviour of "heritage systems". A model can have different aims. A first one is, for example, a descriptive approach, allowing one to better understand the influence of each parameter on the global behaviour of the system. This, naturally conducts to an explanatory stage where the past and present behaviour laws of the system are understood. Lastly a predictive model can be build, in order to predict the behaviour of the system for the forthcoming years and centu- 
ries. Actually these different sorts of models can be combined to describe the complexity of a given system, as for example "multi-agent" approaches. They also can be based on analytical and empirical or phenomenological considerations.

Each of these approaches can concern the so-called: "heritage systems", which behaviours have to be modelled and predicted to propose scenarii for the past evolution of the societies and their environments (historical purpose), or the becoming of human achievements (conservation purpose). These studied systems could be ancient societies or human groups, archaeological landscapes and sites, ancient materials and of course, artefacts and structures that have to be protected and conserved for the future generations.

Models have been used for a long time, for example to understand the properties of materials during their manufacture, as for example glass viscosity (Bingham and Jackson 2008), or thermodynamic phase predominance domains in metallurgy or corrosion. Nevertheless, one of the most exciting challenge for the modelling of "heritage systems" is to link properties and behaviours at different scales. For example, the modelling of the corrosion behaviour of a heritage artefact made of metal needs to understand the nanometer scale properties of the layers formed on the metallic surfaces, but also the climatic evolution of the area where the artefact is stored or exposed. The need of a multiscale approach is actually not a specificity of conservation science or Cultural Heritage approaches, but is a demand in several domains and fields of science and engineering (Yang and Marquardt 2009). In chemical engineering, because of the need to go from a laboratory scaled production to the industrial one, this multiscale approach is relatively popular for several ten years as detailed by Vlachos (Vlachos 2005). In ecology and environmental sciences, some efforts have been made to perform multi-scale approaches to evaluate structures of landscapes (Burnett and Blaschke 2003). For "Heritage systems" as buildings, multiscale modelling combining micro and macro approaches allows to understand ancient building techniques in order to better diagnose the seismic risks (Mele et al. 2003 ; Abruzzese et al. 2009), or understanding the influence of use of some materials (wooden beams reinforcement) for resistance to earthquakes (Kouris and Kappos 2012). In the same area of Cultural Heritage, multiscale data are often used for 3D modelling (Remondino et al. 2009 ; De Luca 2014), but also for the modelling of large and complex archaeological areas (Guidi et al. 2009). Nevertheless, these approaches do not include as large scales gap than the ones that must be involved for other domain of Heritage science as conservation or even multidisciplinary Archaeological sciences. For example, to model the use of resources or materials by ancient societies, to apprehend the qualities of raw materials or artefacts and consequently their technical and economical values, it is necessary to perform analytical studies (referring to Archaeometry or Archaeological science) to assess the nanometric and microscopic composition or structure of the archaeological materials found during excavations (see other chapters). This data can then be included in wider databases, containing information on the different archaeological sites and on the link between the different sites. This holistic analysis of these different kinds of data, collected at different scales (from the nanometre for the chemical composition of the 
artefacts, to the kilometre scale for the archaeological sites), would allow one, in the future, to model the technico-economical developments of ancient societies, based on the use of the data collected on "Heritage systems". Another crucial issue is linked to Cultural Heritage conservation. The aim here, is to make reliable diagnosis to help the restoration decision (Kim et al. 2010 ; Cacciotti et al. 2015). This implies a multidisciplinary interpretation and a comprehensive knowledge based system in which modelling and predicting alteration processes are crucial steps. Here again, both nanometre (molecular interactions) and kilometre (climate) scales must be understood and integrated in a comprehensive multiscale interactive system. Let us develop in the following the different concepts linked with the prediction of the degradation of materials of Cultural Heritage, which is one of the most important challenges for the protection and transmission of Cultural Heritage.

Dealing with corrosion, several holistic multiscale models have been developed linking the behaviour of a given structure to the one of the surfaces involved in the corrosion processes (Cole et al. 2011 ; Cole and Hughes). Inspired from these approaches, models dealing with different kinds of alteration processes could try to describe and predict the behaviour of materials encountered in Cultural Heritage. To that purpose we must identify the processes involved at the different ranges of scales. Inspired by the ones proposed by Cole et al. (Cole et al. 2003) for atmospheric corrosion, it is possible to propose seven scales to model processes (Fig. 32):

- Macro: linked to gross meteorological conditions (polar, tropical continental, etc.).

- Meso: meteorological parameters concerning regions of about $100 \mathrm{~km}^{2}$ (marine, urban, rural, etc.).

- Local: immediate vicinity of the artefact, the building or the site.

- Micro: absolute proximity of the surface material.

- Surface: physical response of the surface (deposition an retention of pollutants, condensation, evaporation), radiation (sun, lights).

- Micron: interaction within interfaces in the material (material/electrolyte), charge and mass transfer and transport phenomena (in electrolyte).

- Nanometer: chemical reactions, charge and mass transfers, transport phenomena (in the solid).

Different sub-models could then be defined, linked to each of their scale. Concerning the macro and meso-stage, to our knowledge, no model was directly developed in the field of conservation science, except the one developed by Tidblad et al. (Tidblad 2013) to predict the effect of climatic change on corrosion of metals. Nevertheless, already existing ones could be used in a forthcoming holistic approach. For example some modules developed by Cole et al. (Cole et al. 2003) can be used for metals but probably also for a wide range of other materials. Up to now, models already developed in the domain of conservation of Cultural Heritage 
deals only with a single stage and the largest scale is the one corresponding to local conditions.

For example, de la Fuente et al. (de la Fuente et al. 2011), aims to assess and predict the effect of different pollutants on materials and object of the Cultural Heritage. Depending on the variation of concentration of different pollutants $\mathrm{SO}_{2}$, $\mathrm{NO}_{2}, \mathrm{O}_{3}$ and PM10-Particulate Matter with size bellow $\left.10 \mu \mathrm{m}\right)$ and the alteration rate observed on different kinds of materials (bronze, limestone, ...), dose response functions were empirically established. They allowed one to propose maps corresponding to different scenarios of pollutions and damages.

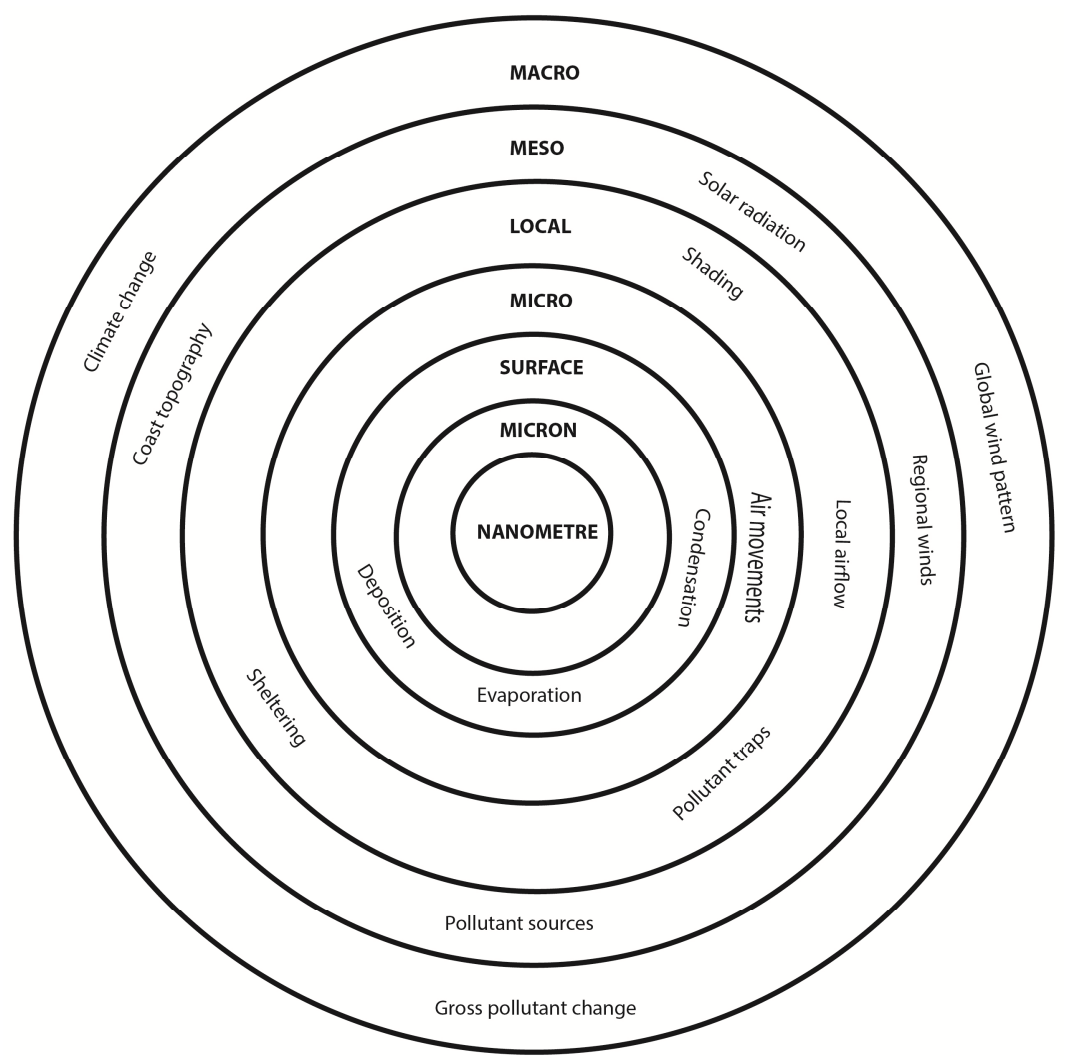

Fig. 32. Framework for an holistic model of alteration of Cultural Heritage (inspired from Cole et al. 2003)

At the "micro" scale, the 3D models on buildings, as the one developed by Stefani et al. (Stefani et al. 2014) on the Chambord Castle, can be helpful to locate the different degradation patterns by efficient alteration mapping and to link them to local environmental variations. This is the first step to build models at the "micro" and "surface" stages of the Cole's scale. Then, the local variations can be linked to modelled variation of outdoor or indoor atmospheres. Considering in- 
door atmosphere of buildings and museums, some attempt has been made to model the evolution of heat and moisture using meteorological data, building properties and users behaviour and a combination of a hydrothermal simulation and finite element approach (Huijbregts et al. 2015). Another example linked to that scale of interest: the modelling of the temperature and humidity distribution by computational fluid dynamic based on finite volumes methods in the Hall of the Domus Aurea in Rome (Albero et al. 2004). At the "surface" levels, three dimensional computational fluid dynamics model were used to understand the influence of thermohygrometric parameters and airflow patterns responsible for salt recrystallization in the stones of the Crypt of the Lecce Cathedral in South Italy (D'Agostino et al. 2014). At the "micron" scale, several models dealing with local chemical processes have been developed. For example, to understand the reaction of sulphur dioxide from the atmosphere with calcareous porous stones (found for example in statuary) the models considered reactivity and diffusion of species to give a behaviour law and a quantitative description of the processes by 3D simulation (Giavarini et al. 2008). Parameters as crucial as diffusion coefficient of some species were collected and are used to serve modelling of processes at this stage. For example this was performed in a study on bronze corrosion in sulphate medium in order to understand the influence of tin content on corrosion processes (Muller et al. 2013). An analytical model of the long term corrosion of iron reinforcement embedded in hydraulic binders using parameters directly measured on archaeological artefacts was proposed by Chitty et al. (Chitty et al. 2008a; Chitty et al. 2008b). This model considers the kinetic of oxygen diffusion through the system and its consumptions at the metal/corrosion product interface. Also dealing with corrosion of iron from Cultural Heritage buildings, Monnier et al. (Monnier et al. 2010) proposed a phenomenological model based on the establishment of a reactivity index of the constitutive phases of the corrosion layers formed on the artefacts. Several models involving the nanoscale have been proposed to describe long term corrosion of iron. They are constructed by taking into account a limiting step, for example the presence of a corrosion layer or nanopores hindering transport at this level (Hoerlé et al. 2004 ; Bataillon et al. 2010). Another phenomenological model for long term prediction at "micron" and "nano" scales was also developed for glasses in the context of the deep storage of nuclear wastes (VerneyCarron et al. 2010). This latter one involves nanometer scale phenomenology to understand and predict the formation of a protective gel at the surface of the glass depending on the solution of the water of the surrounding medium (clay). These three latter models were developed after analytical and parametric studies on archaeological and heritage metallic/glassy artefacts despite their application domains are not directly linked to the conservation of Cultural Heritage. Thus, they can perfectly be transposed back to "heritage systems" with the advantage to directly address "realistic" materials and conditions by directly exploiting the formalisms of the developed models.

This short review clearly shows that, by combining all these different scales, from global climatic changes to nano properties of the heritage systems, it would be possible in the next future, at least for several kinds of these systems, to pro- 
pose such an holistic model. This new challenge could be a wonderful mean to federate research teams around a global interdisciplinary project for conservation of Cultural Heritage.

Nevertheless, these kinds of holistic models could only be achievable by using consolidated databases containing heterogeneous data. Thus, one of the next forthcoming challenge, dealing with all sort of data (from climatic change to nanoscale measurements), is to construct perennial and interoperable databases. Several research teams are now on that path but this objective can only be achievable with a coordination at a national or European level for example.

Last but not least, any model has to be validated. Considering predictive models aiming to predict the behaviour of heritage systems on several 10 years or even centuries, this validation could be a real breakthrough. One solution could be a retroactive approach, considering the behaviour of the system in the past, studying "analogues", for benchmarking. These challenge linked with long term prediction is also one of the most exciting one for researches in the future.

This multistep and multiscale approach for predictive modelling will have to face several challenges to reach the goal. First it has to be stressed that the link between the fine characterisation of mechanisms and the properties of the system and the numerical modelling must constantly be preserved by regular come and go between all the concerned disciplines. This could be implemented in the future in the frame of global interdisciplinary projects dealing with one kind of material (metal, stone, etc.) in a given environment. This kind of project have a sense at the European scale and must gather all the specialists from laboratories skilled in fine and multiscale characterisation to teams specialised in numerical modelling. We believe that it is only in that frame that the synergies between all disciplines will be found. Another crucial aspect, we can think that in the future these new model for predicting the evolution of heritage systems with environment and climate can be considered as a new kind of immaterial Cultural Heritage, in the same way that the digitalised museums or libraries collections. This new "digitalised" Cultural Heritage resource, allowing future generation of scientist to develop and use predictive models will be based on the mastering of international and multi-source databases. This other aspect constitutes also an exciting challenge for future generations that could be faced at the European scale by gathering research and engineering teams using European facilities for data storage and treatment.

\section{References}

Abruzzese D, Miccoli L, Yuan J (2009) Mechanical behavior of leaning masonry Huzhu Pagoda. Journal of Cultural Heritage 10:480 - 486. doi:http://dx.doi.org/10.1016/j.culher.2009.02.004

Albero S, Giavarini C, Santarelli ML, Vodret A (2004) \{CFD\} modeling for the conservation of the Gilded Vault Hall in the Domus Aurea. Journal of Cultural Heritage 5:197 - 203. doi:http://dx.doi.org/10.1016/j.culher.2003.08.001 
Ambrosi M, Dei L, Giorgi R, Neto C, Baglioni P (2001) Colloidal Particles of $\mathrm{Ca}(\mathrm{OH}) 2$ : Properties and Applications to Restoration of Frescoes. Langmuir 17 (14):4251-4255. doi:10.1021/la010269b

Astruc L, Vargiolu R, Tkaya MB, Balkan-Atlı N, Özbaşaran M, Zahouani H (2011) Multi-scale tribological analysis of the technique of manufacture of an obsidian bracelet from Aşıklı Höyük (Aceramic Neolithic, Central Anatolia). Journal of Archaeological Science 38 (12):3415-3424

Baglioni P, Chelazzi D, Giorgi R, Poggi G (2013) Colloid and Materials Science for the Conservation of Cultural Heritage: Cleaning, Consolidation, and Deacidification. Langmuir 29 (17):5110-5122. doi:10.1021/la304456n

Bataillon C, Bouchon F, Chainais-Hillairet C, Desgranges C, Hoarau E, Martin F, Perrin S, Tupin M, Talandier J (2010) Corrosion modelling of iron based alloy in nuclear waste repository. Electrochimica Acta 55 (15):4451-4467

Bayle M (2015) Déchloruration des objets archéologiques ferreux par le processus de stabilisation subcritique - Caractérisations physico-chimiques des systèmes transformés. Pierre et Marie Curie University, $\mathrm{PhD}$ Thesis

Bernard S, Benzerara K, Beyssac O, Brown GE (2010) Multiscale characterization of pyritized plant tissues in blueschist facies metamorphic rocks. Geochimica Et Cosmochimica Acta 74 (17):5054-5068. doi:10.1016/j.gca.2010.06.011

Bertholon R (2001) The original surface of corroded metallic archaeological objects: characterization and location. La Revue de Métallurgie 9:817-823

Bingham PA, Jackson CM (2008) Roman blue-green bottle glass: chemical-optical analysis and high temperature viscosity modelling. Journal of Archaeological Science 35:302 - 309. doi:http://dx.doi.org/10.1016/j.jas.2007.03.011

Brauns M, Schwab R, Gassmann G, Wieland G, Pernicka E (2013) Provenance of Iron Age iron in southern Germany: a new approach. Journal of Archaeological Science 40 (2):841-849. doi:http://dx.doi.org/10.1016/j.jas.2012.08.044

Burnett C, Blaschke T (2003) A multi-scale segmentation/object relationship modelling methodology for landscape analysis. Ecological Modelling 168:233 - 249. doi:http://dx.doi.org/10.1016/S0304-3800(03)00139-X

Cacciotti R, Blaško M, Valach J (2015) A diagnostic ontological model for damages to historical constructions. Journal of Cultural Heritage 16:40 - 48 . doi:http://dx.doi.org/10.1016/j.culher.2014.02.002

Casadio F, Van Duyne RP (2013) Molecular analysis for art, archaeometry and conservation. Analyst 138 (24):7276-7278.

Cersoy S, Richardin P, Walter P, Brunelle A (2012) Cluster TOF-SIMS imaging of human skin remains: analysis of a South-Andean mummy sample. Journal of Mass Spectrometry 47 (3):338-346. doi:10.1002/jms.2979

Chalmin E, Menu M, Pomiès M-P, Vignaud C, Aujoulat N, Geneste J-M (2004) Les blasons de

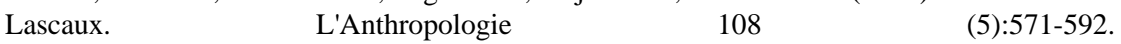
doi:http://dx.doi.org/10.1016/j.anthro.2004.12.001

Chalmin E, Vignaud C, Salomon H, Farges F, Susini J, Menu M (2006) Minerals discovered in paleolithic black pigments by transmission electron microscopy and micro-X-ray absorption near-edge structure. Applied Physics A 83 (2):213-218. doi:10.1007/s00339-006-3510-7

Chelazzi D, Poggi G, Jaidar Y, Toccafondi N, Giorgi R, Baglioni P (2013) Hydroxide nanoparticles for cultural heritage: Consolidation and protection of wall paintings and carbonate materials. Journal of Colloid and Interface Science 392 (0):42-49. doi:http://dx.doi.org/10.1016/j.jcis.2012.09.069

Chitty W-J, Berger P, Dillmann P, L'Hostis V (2008a) Long-term corrosion of rebars embedded in aerial and hydraulic binders - Mechanisms and crucial physico-chemical parameters. Corrosion Sci 50 (8):2117-2123

Chitty W-J, Dillmann P, L'Hostis V, Millard A (2008b) Long-term corrosion of rebars embedded in aerial and hydraulic binders - Parametric study and first step of modelling. Corrosion Sci 50 (11):3047-3065 
Cole IS, Hughes AE Designing molecular protection: new paradigm for developing corrosion resistant materials uniting high throughput studies, multiscale modelling and self-repair. Corrosion Engineering Science and Technology 49:109-115

Cole IS, Muster TH, Azmat NS, Venkatraman MS, Cook A (2011) Multiscale modelling of the corrosion of metals under atmospheric corrosion. Electrochimica Acta 56:1856-1865

Cole IS, Paterson DA, Ganther WD (2003) Holistic model for atmospheric corrosion Part 1 Theoretical framework for production, transportation and deposition of marine salts. Corrosion Engineering, Science and Technology 38:129-134. doi:10.1179/147842203767789203

Colombini MP, Modugno F (2009) Organic materials in art and archaeology. In: Colombini MP, Modugno F (eds) Organic Mass Spectrometry in Art and Archaeology. John Wiley \& Sons, Ltd, pp 1-36.

Crina Anca Sandu I, de Sá MH, Pereira MC (2011) Ancient 'gilded' art objects from European cultural heritage: a review on different scales of characterization. Surface and Interface Analysis 43 (8):1134-1151. doi:10.1002/sia.3740

D’Agostino D, Congedo PM, Cataldo R (2014) Computational fluid dynamics (CFD) modeling of microclimate for salts crystallization control and artworks conservation. Journal of Cultural Heritage 15:448 - 457. doi:http://dx.doi.org/10.1016/j.culher.2013.10.002

Dal Bianco B, Bertoncello R (2008) Sol-gel silica coatings for the protection of cultural heritage glass. Nuclear Instruments and Methods in Physics Research Section B: Beam Interactions $\begin{array}{llll}\text { with Materials atoms } & & \end{array}$ doi:http://dx.doi.org/10.1016/j.nimb.2008.03.014

de la Fuente D, Díaz I, Simancas J, Chico B, Morcillo M (2011) Long-term atmospheric corrosion of mild steel. Corrosion Sci 53 (2):604-617. doi:10.1016/j.corsci.2010.10.007

De Luca L (2014) Methods, formalisms and tools for the semantic-based surveying and representation of architectural heritage. Applied Geomatics 6:115-139. doi:10.1007/s12518-0110076-7

De Stasio G, Gilbert B, Frazer BH, Nealson KH, Conrad PG, Livi V, Labrenz M, Banfield JF (2001) The multidisciplinarity of spectromicroscopy: from geomicrobiology to archaeology. Journal of Electron Spectroscopy and Related Phenomena 114-116 (0):997-1003. doi:http://dx.doi.org/10.1016/S0368-2048(00)00369-8

Dejoie C, Tamura N, Kunz M, Goudeau P, Sciau P (2015) Complementary use of monochromatic and white-beam X-ray micro-diffraction for the investigation of ancient materials. Journal of Applied Crystallography 48 (5):1522-1533. doi:doi:10.1107/S1600576715014983

Dillmann P, Bellot-Gurlet L (2014) Circulation et provenance des matériaux dans les sociétés anciennes. Sciences Archéologiques. Editions Archives Contemporaines Paris

Edwards H, Vandenabeele P (2012) Analytical archaeometry: selected topics. Royal Society of Chemistry, Cambridge

Evershed RP (2008) ORGANIC RESIDUE ANALYSIS IN ARCHAEOLOGY: THE ARCHAEOLOGICAL BIOMARKER REVOLUTION*. Archaeometry 50 (6):895-924

Fleischer M (2012) Near-field scanning optical microscopy nanoprobes. Nanotechnology Reviews, vol 1. doi:10.1515/ntrev-2012-0027

Galvez ME, Benzerara K, Beyssac O, Bernard S (2009) Chemical and structural imaging of fossilized tissues at the nanoscale and assessment of their taphonomy. Geochimica Et Cosmochimica Acta 73 (13):A408-A408

Giachi G, Bugani S, Łucejko J, Modugno F, Tatti F Different techniques (SR- $\mu$ CT, SEM, FIB/SEM) for the evaluation of the deposition of impregnating substances into waterlogged archaeological wood, woodcutter.com.

Giavarini C, Santarelli ML, Natalini R, Freddi F (2008) A non-linear model of sulphation of porous stones: Numerical simulations and preliminary laboratory assessments. Journal of Cultural Heritage 9:14 - 22. doi:http://dx.doi.org/10.1016/j.culher.2007.12.001

Guidi G, Remondino F, Russo M, Menna F, Rizzi A, Ercoli S (2009) A Multi-Resolution Methodology for the 3D Modeling of Large and Complex Archeological Areas. International Journal of Architectural Computing 7:39-55. doi:10.1260/147807709788549439 
Hélary D, Darque-Ceretti E, Bouquillon A, Aucouturier M, Monge G (2003) Contribution de la diffraction de rayons $\mathrm{X}$ sous incidence rasante à l'étude de céramiques lustrées. Revue d'Archéométrie:115-122

Hoerlé S, Mazaudier F, Dillmann P, Santarini G (2004) Advances in Understanding Atmospheric Corrosion of Iron II - Mechanistic Modelling of Wet-Dry Cycles. Corrosion Sci 46 (6):14311465

Hoppe, P., Cohen, S., \& Meibom, A. (2013). NanoSIMS: technical aspects and applications in cosmochemistry and biological geochemistry. Geostandards and Geoanalytical Research, 37(2), 111-154

Huijbregts Z, Schellen H, Schijndel Jv, Ankersmit B (2015) Modelling of heat and moisture induced strain to assess the impact of present and historical indoor climate conditions on mechanical degradation of a wooden cabinet. Journal of Cultural Heritage 16:419 - 427. doi:http://dx.doi.org/10.1016/j.culher.2014.11.001

Kim C-J, Yoo WS, Lee U-K, Song K-J, Kang K-I, Cho H (2010) An experience curve-based decision support model for prioritizing restoration needs of cultural heritage. Journal of Cultural Heritage 11:430 - 437. doi:http://dx.doi.org/10.1016/j.culher.2010.03.004

King HE, Mattner DC, Plümper O, Geisler T, Putnis A (2014) Forming Cohesive Calcium Oxalate Layers on Marble Surfaces for Stone Conservation. Crystal Growth \& Design 14 (8):3910-3917. doi:10.1021/cg500495a

Kouris LAS, Kappos AJ (2012) Detailed and simplified non-linear models for timber-framed masonry structures. Journal of Cultural Heritage 13:47 - 58. doi:http://dx.doi.org/10.1016/j.culher.2011.05.009

Kurouski D, Zaleski S, Casadio F, Van Duyne RP, Shah NC (2014) Tip-Enhanced Raman Spectroscopy (TERS) for in Situ Identification of Indigo and Iron Gall Ink on Paper. Journal of the American Chemical Society 136 (24):8677-8684. doi:10.1021/ja5027612

Leon Y, Saheb M, Drouet E, Neff D, Foy E, Leroy E, Dynes JJ, Dillmann P (2014) Interfacial layer on archaeological mild steel corroded in carbonated anoxic environments studied with coupled micro and nano probes. Corrosion Sci 88:23-35. doi:10.1016/j.corsci.2014.07.005

Leon Y, Sciau P, Passelac M, Sanchez C, Sablayrolles R, Goudeau P, Tamura N (2015) Evolution of terra sigillata technology from Italy to Gaul through a multi-technique approach. Journal of Analytical Atomic Spectrometry 30 (3):658-665. doi:10.1039/C4JA00367E

Leroy S, Cohen SX, Verna C, Gratuze B, Téreygeol F, Fluzin P, Bertrand L, Dillmann P (2012) The medieval iron market in Ariège (France). Multidisciplinary analytical approach and multivariate analyses. Journal of archaeological science 39 (4):1080-1093

Madariaga JM (2015) Analytical chemistry in the field of cultural heritage. Analytical Methods 7 (12):4848-4876.

Manoudis PN, Karapanagiotis I, Tsakalof A, Zuburtikudis I, Kolinkeová B, Panayiotou C (2009) Superhydrophobic films for the protection of outdoor cultural heritage assets. Applied Physics A 97 (2):351-360. doi:10.1007/s00339-009-5233-z

Mele E, Luca AD, Giordano A (2003) Modelling and analysis of a basilica under earthquake loading. Journal of Cultural Heritage 4:355 - 367. doi:http://dx.doi.org/10.1016/j.culher.2003.03.002

Monnier J, Dillmann P, Legrand L, Guillot I (2010) Corrosion of iron from heritage buildings: proposal for degradation indexes based on rust layer composition and electrochemical reactivity. Corrosion Engineering Science and Technology 45 (5):375-380

Muller J, Laïk B, Guillot I (2013) $\alpha$-CuSn bronzes in sulphate medium: Influence of the tin content on corrosion processes. Corrosion Sci 77:46 - 51 . doi:http://dx.doi.org/10.1016/j.corsci.2013.07.025

Physical techniques in the study of Art, Archaeology and Cultural Heritage (2006), vol Volume 1. Elsevier, Amsterdam

Pollard AM, Heron C (2008) Archaeological chemistry. Royal Society of Chemistry,

Pomiès MP, Menu M, Vignaud C (1998) TEM observations of goethite dehydratation: allpication to archaeological samples. Journal of the Eurpean Ceramic Society 19:1605-1614 
Remondino F, Girardi S, Rizzi A, Gonzo L (2009) 3D Modeling of Complex and Detailed Cultural Heritage Using Multi-resolution Data. J Comput Cult Herit 2:2:1-2:20. doi:10.1145/1551676.1551678

Richardin P, Mazel V, Walter P, Laprévote O, Brunelle A (2011) Identification of Different Copper Green Pigments in Renaissance Paintings by Cluster-TOF-SIMS Imaging Analysis. J Am Soc Mass Spectrom 22 (10):1729-1736. doi:10.1007/s13361-011-0171-3

Sakdinawat A, Attwood D (2010) Nanoscale X-ray imaging. Nat Photon 4 (12):840-848

Silversmit G, Vekemans B, Brenker FE, Schmitz S, Burghammer M, Riekel C, Vincze L (2009) X-ray Fluorescence Nanotomography on Cometary Matter from Comet 81P/Wild2 Returned by Stardust. Anal Chem 81 (15):6107-6112. doi:10.1021/ac900507x

Stefani C, Brunetaud X, Janvier-Badosa S, Beck K, Luca LD, Al-Mukhtar M (2014) Developing a toolkit for mapping and displaying stone alteration on a web-based documentation platform. Journal of Cultural Heritage 15:1 - 9. doi:http://dx.doi.org/10.1016/j.culher.2013.01.011

Thoury M, Echard J-P, Réfrégiers M, Berrie B, Nevin A, Jamme F, Bertrand L (2011) Synchrotron UV-Visible Multispectral Luminescence Microimaging of Historical Samples. Anal Chem 83 (5):1737-1745. doi:10.1021/ac102986h

Tidblad J (2013) Atmospheric corrosion of heritage metallic artefacts: processes and prevention. In: Corrosion and conservation of cultural heritage metallic artefacts. EFC Series. Woodhead Publishing, Oxford, pp 37-52

Ungár T, Martinetto P, Ribárik G, Dooryhée E, Walter P, Anne M (2002) Revealing the powdering methods of black makeup in Ancient Egypt by fitting microstructure based Fourier coefficients to the whole x-ray diffraction profiles of galena. Journal of Applied Physics 91 (4):2455-2465. doi:doi:http://dx.doi.org/10.1063/1.1429792

Verney-Carron A, Gin S, Frugier P, Libourel G (2010) Long-term modeling of alterationtransport coupling: Application to a fractured Roman glass. Geochimica Et Cosmochimica Acta 74 (8):2291-2315

Villanueva-Amadoz U, Benedetti A, Méndez J, Sender LM, Diez JB (2012) Focused ion beam nano-sectioning and imaging: a new method in characterisation of palaeopalynological remains. Grana 51 (1):1-9. doi:10.1080/00173134.2011.641579

Vlachos DG (2005) A Review of Multiscale Analysis: Examples from Systems Biology, Materials Engineering, and Other Fluid-Surface Interacting Systems. In: Marin GB (ed) Advances in Chemical EngineeringMultiscale Analysis, vol 30. Advances in Chemical Engineering. Academic Press, pp 1 - 61

Yang A, Marquardt W (2009) An ontological conceptualization of multiscale models. Computers \& Chemical Engineering:822-837 